\title{
Current State and Problems Faced in Chinese Teaching in Belgium
}

\author{
Hongjuan Liu \\ International College of Qujing Normal University, Yunnan, China \\ 763678246@qq.com
}

Keywords: Belgium; Teaching institution; Chinese language teaching; Achievement; Problem

\begin{abstract}
There are many Chinese teaching institutions in Belgium,including universities, Confucius Institutes, Chinese schools for children and adults, evening classes in Universities etc. Combining the information provided by the Chinese Education Sector in Belgium and my interview outcome with the local Chinese teachers. This thesis mainly focuses on introducing the current state of these institutions in terms of their education system, management system, faculty construction and its history.Therefore we can get the conclusion that Belgium has made tremendous achievement in terms of Chinese education, management and teachers resources. At the same time, there is room for improvement. For example, both of KU.Leuven University and Gent University which have set up their own Sinology departments and feature a long history of formal Chinese education fail to demonstrate their focuses from the curriculum's point of view; All the Confucius Institute should think about how to complement and cooperate with other Chinese teaching organizations in a harmonious manner and pave the way for their future work; Some of the Chinese teachers in Chinese teaching institute have never received proper teaching qualifications.
\end{abstract}

\section{Introduction}

Belgium, officially the Kingdom of Belgium is located in North Western part of Europe. Belgium covers an area of 30,528 square kilometers and has a population of over 11 million people. Economically, Belgium enjoys great success although it is not a big country with many inhabitants. There are three official languages, which are French, Dutch and German due to its unique political, geographical and religious reasons. An Estimated 56\% of the Belgian population speaks Dutch, and $41 \%$ of the population speaks French, and $1.5 \%$ of the population speaks German. A number of non-official minority languages are spoken as well such as Arabic, Turkish, Italian, Portuguese and other Eastern European languages. Therefore, Belgian children grow up in multilingual environment and many of them speak two or three or even more languages. For example, French speaking children tend to choose Dutch speaking pre-school or primary school. Or if they do not choose go to Dutch speaking school, It's compulsory for them to choose another official language starting from year five. Students from the French community must choose Dutch or English as their first foreign language in the secondary school. Also they have to choose a second foreign language from options such as German, Latin, Greek, Dutch or English. The same rule applies in the Dutch community. The only difference would be students must take French as their first foreign language and then choose another second foreign language. Usually, students from German community would choose Dutch, French or English as their second language to learn. In a word, we could say that most Belgians are language geniuses with multilingual talents.

Although Belgian students undertake extremely heavy language tasks, Chinese learning has gained importance and has been promoted widely in Belgium. According to incomplete statistics, there are a total of 200 Chinese teachers living in Belgium consist of local teachers, Chinese teachers who have migrated there and teachers delegated by Han Ban. There are 8 overseas volunteer teachers and approximately 3,000 students learning Chinese. There are over 100 Chinese teaching organizations, among which five universities have set up their Chinese department or have Chinese related subjects. 
There are four Confucius Institutes. In addition, there are eight Chinese schools whose students are mainly from the Chinese community. On top of that, there are over 40 Chinese organizations offering classes to adults or evening classes in universities. Initially there were only 8 Belgian secondary schools offer Chinese classes due to students' heavy language learning duty. However, thanks to the support and effort made by Han Ban, Confucius Institute Headquarters and the Education Division of the Chinese Embassy in Belgium. 10 Chinese learning centers have been set up in the secondary schools in the Dutch region. Since Belgian Education Department in the French Region launched'Language et Culture'd Origine Program' in September 2011, about 42 primary and secondary schools and kindergartens joined in this program and have set up their Chinese language and Culture classes. It is worth mentioning that there is a new rule written in Compulsory Education Syllabus for 2014-2015 which was formulated by Belgian Education Department. It says that Chinese language can be taken as a foreign language optional course in the secondary schools for students from grade 3 to grade 6. Once the number of applicants is more than 8 , Chinese language courses can be set up in students' school time. There are also 3 secondary schools from Dutch region that set up Chinese language courses in students' school time.(Datas are provided by Chinese Education Sector in Belgium).

\section{Review of Chinese Education Research in Belgium}

We reviewed previous research journal database data on the education situation in Belgium and found that most of the articles are the overall presentation of the education situation in Belgium(Chinese Education Sector in Belgium.1996)[1]. Some of them are devoted to higher education or adult education in this country(Song,2004; Yu\&Yu,1997; Ma,1998)[2][3]. Some of them use specific examples to showcase certain aspects of the education(Zi,2004; Ma,1998)[4][5]. Articles associated with China are mainly comparing the similarities and differences between Chinese and Belgian schools in terms of education and teaching methods(Li,2002)[6]. I only found four articles (Bart Dessein,1998; Shen, 2011; Liu\&Zhang, 2013; Liu, 2012; )[7][8][9] that totally focused on Chinese language education in Belgium, which will be discussed below.

Professor Bart Dessein (Bart Dessein,1998)from Gent University wrote "Chinese Institutions in Belgium" in 1998. The paper covers the basic situation, publications and contact details of a few Chinese teaching institutions in Belgium[7]. Mr Shen(Shen, 2011) wrote "Overseas Chinese Intermediate Speaking Teaching Strategies - Case Study on Sinology Department of Gent University”. In this article, Mr Shen proposed unique strategies towards intermediate spoken Chinese teaching, based on the specific teaching environment and target audience in Gent University[10]. The above two articles mainly delved into certain micro-level study of Chinese education in Belgium. Personally, I was involved in writing the other two papers, which are focused on the macro-level study of Chinese Education in Belgium. One of them is called "Sinology Research and Chinese Education in Belgium Universities"(Liu\&Zhang, 2013). This paper covers the Chinese research and education situation in both Leuven University and Gent University, including details such as Chinese teachers and students, textbooks, education concept, curriculum, testing system and a comparison drawn between these two universities[8]. The other one is called "Chinese Teaching in Belgium"(Liu, 2012). It mainly focuses on Chinese education institutions, including aspects such as target students, teaching time and education philosophy etc[9].

This article is written based on my two previous papers, through collecting latest data and combining with my own contemplation. Therefore, this article is mainly focused on current issues and solutions facing the Chinese institutions in Belgium. Hope this will provide a reference for the development of overseas Chinese education in Belgium and other countries. 


\section{Research Methods}

Participants. Retired Chinese teachers Leuven University and Gent University in Belgium. Among which two teachers understand the Chinese teaching history very well because they are the first year graduates from the Sinology Department of Leven University. Principals or Deputy Principals of each Confucius Institutes. They give very detailed information about the programs and enrollment of their institutes.Teachers from Adult Evening Schools and Chinese Schools,Staffs from the Education Sector of Chinese Embassy in Belgium.

Data Collection. The data for this article was mainly collected through questionnaires and interviews. Questionnaire includes questions on curriculum setting, examination system, composition of teachers and students, teaching materials, Chinese Culture activities and suggestions for current Chinese education etc. Interviewees include two Chinese teachers from the Sinology Department of the Leuven University and they are the first year graduates from the Sinology Department of Leven University, as well as another teacher from the Education Sector of Chinese Embassy in Belgium. The purpose for interviewing the first two Chinese teachers is to understand the Chinese education development made in Leuven University as it boasts a long and proud history in Chinese teaching achievements and its focus on the reasons to achieve such impressive outcomes. The latter interview aims to understand the basic Chinese teaching situation in Belgium as a whole and explores its shortcomings. There is some limitation on these data collected due to the difficulty in carrying out in-depth interviews with staff from each Chinese teaching institution.

\section{Discussion of Current State and Problems Faced in Chinese Teaching in Belgium}

Characteristics of Various Types of Chinese Language Teaching Institutions in Belgium. Among all the Chinese language teaching institutions in Belgium, universities enjoy the most stable source of students and have the most structured teaching method with the best quality of teaching. So far there are five universities offer Chinese related subjects or have set up their Sinology department. Both KU Leuven and University Gent have set up their own Sinology departments and feature a long history of formal Chinese education. The other three colleges established a major in translations between English and Chinese.

The Sinology department of KU Leuven was founded in 1979. However, as early as the 16th century, before the Kingdom of Belgium became independent, KU Leuven University already started to offer oriental language course. Back then, the University was known as 'de Leuvense Universiteit' . Most Chinese learners and teachers at that time were Jesuit missionaries, who also served as the culture bridge between western and eastern world. Initially, there were over 30 people enrolled in the first year when the Sinology department was established. The new students' number rose to approximately 100 in 2005 and 2006 after China won the bidding for the Olympic Games. Since 2007, new students' number stayed around 50 to 60 on annual basis. Generally, students need to go through four years of study in the Sinology department. Students will be awarded bachelor degree once they complete the first three years. The fourth year is considered to be post graduate studies and students will obtain their certificates upon completing relevant thesis. In order to have more work opportunities, students usually choose a secondary subjects such as Economics or Culture related subjects apart from focusing on their linguistic degree. Therefore, students also fall into two different categories i.e. economic group and cultural group. The majority of the students would opt for pursuing further Chinese studies in the universities in China when they complete their bachelor's degree. A number of them would continue to finish their postgraduate studies upon return from China. Some of them would choose to focus on studying economics or cultural related subjects in order to get masters degree in these areas. The rest of the students would choose to go to work upon finishing their bachelor's degree. Teachers who work in the Sinology department of KU Leuven are either Belgian locals or Chinese immigrants or teachers allocated by Han Ban. Most of the teachers for the first year students are local Belgian teachers. In 
particular, local teachers teach Chinese grammar in Dutch and Chinese. This way, students are more relaxed and receptive in learning Chinese. It works well for Belgium as there is no entrance test for universities and colleges. (Exceptions include medicine and engineering majors). Students could be on very different levels of learning. The Sinology department of KU Leuven aims to nurture students so they all have good communication skills in Chinese language. Usually, the test elimination rate in the first year is quite high and could be up to $40 \%$ or $50 \%$. From second year onwards, more and more classes are taught by Chinese native teachers, especially in the third and fourth year, basically all the classes are taught in Chinese apart from the Dutch and Chinese translation class. This way, it's also very beneficial to improve students listening and speaking skills. The Sinology department of KU Leuven emphasizes on vivid language materials, there are no reference textbooks used in classes. Teachers usually prepare their own course materials that would be interesting and appealing to students. There is a strong emphasis on students' pronunciation. Students from KU Leven University are famous for their accurate pronunciation and strong Chinese communication skills. Several students from KU Leuven won a special award or first prize in Hanyu Qiao Competition.Of course, these excellent results demonstrated that students from Leuven University's Sinology department do have strong listening and speaking skills.Many graduates from this department work in the embassy or companies where they can use Chinese. Some of them work for Belgian Consulate General or embassies in China. In recent years, an increasing number of them choose to go to work in China for companies dealing with Begian business. Generally speaking, there is a considerable number of graduates working in areas that are not related to Chinese or China. This is also considered to be an important factor to restrict the number of people from choosing Chinese as their major or applying for their masters degree for those who have done undergraduate studies in Chinese. Following Prince Philip's visit to China with his trade delegation, we are hoping to see more Chinese related job opportunities in Belgium.

Sinology Department of University Gent belongs to the Oriental Languages and Cultures Department. Towards the end of 19th century, since some Belgian companies began to seek development in China, Charles Woeste, who was a member of Belgium parliament at that time, proposed to set up Asian language courses at the Universities of Belgium. Under such a backdrop, University Gent started to offer Chinese courses in 1900. Like Sinology department of KU Leuven, University Gent also offers bachelors degree and masters degree studies. Students can choose to do another degree apart from focusing on their Chinese studies. In the third year of their studies, students can choose to do one semester of their studies in Liaoning University in China.The credits they earn from Liaoning University can be seen as part of their degree credits. In comparison with KU Leuven, University Gent focuses more on linguistic knowledge and literature, while KU Leuven focuses more on students' practical Chinese communication skills. Therefore, courses such as ancient Chinese, literature and culture account for a large proportion of all the courses in this department, while modern Chinese course accounts for a large proportion in KU Leuven.

There are six Confucius Institutes in Belgium, including Brussels Confucius Institute, Liege Confucius Institute, Leuven Confucius Institute, Bruges Confucius Institute, VUB Confucius Institute and ULB Confucius Institute. They are spread all over three main language regions of Belgium, for example Leuven, Bruges and VUB Confucius Institute belong to the Dutch-speaking region, Liege and ULB Confucius Institute belong to the French-speaking region and Brussels Confucius Institute belongs to the Bilingual region. Most of their courses were taught in the evenings. Levels vary from beginners to advanced level. Most of the teachers in these institutes are local Belgian teachers, Chinese immigrants and volunteers allocated by Han Ban. The main textbook used for non-adult classes isHappy Chinese (in Chinese: Kuai Le Han Yu), and the textbooks used for adult classes are various. There are different kinds of students in these Confucius Institutes, such as social workers, university students, primary and secondary school students and so on. Apart from the regular Chinese language teaching courses, each Confucius Institute also plays its own unique role in promoting Chinese language teaching and culture. For instance, Brussels Confucius Institute started a series of interesting 
courses, such as Chinese history, Chinese calligraphy, qigong, martial arts and so on. Meanwhile, they also work together with some Belgian local primary and secondary schools to set up a variety of Chinese language courses and provide teachers and resources to them. Leuven Confucius Institute has committed to cooperate with primary and secondary schools in Dutch speaking region, including developing and promoting the suitable Chinese textbooks to their students, providing free culture courses and son on. Last but not the least, together with Belgian Chinese Language Association, it hosts an annual workshop for Chinese teachers working in Belgium. In cooperation with the Chinese Students and Scholars Association, Leuven Confucius Institute also organizes the Chinese New Year Gala which is always a highlight of their work. Not only this is a good opportunity to showcase the Chinese traditional festival features but also provide a good platform for Belgian Chinese to socialize with each other. Liege Confucius Institute offers Chinese linguistic and modern Chinese culture courses (optional) to students from Liege University and hosts a series of lectures, exhibitions and conferences that of Chinese relevance.

The main target students of the weekend Chinese school in Belgium are children from overseas Chinese. Either both parents are Chinese or one parent is Chinese. Most students have certain target language environment at home. Some students are even able to converse in Chinese mandarin using simple daily language. The reason for parents sending their children to the weekend Chinese school is to improve their language skills, and most importantly, they want their kids to have a deeper understanding of Chinese cultures and never forget their roots. The teaching hours are generally on weekends or on Wednesday's afternoon when there are no classes for primary and secondary schools. Each class lasts three hours. There are primary sector and secondary sector depending on students' age. Some individual schools also offer adult courses such as Zhejiang Industrial and Commercial Association Chinese School in Liege. Each sector would divide the students into different classes according to their learning level. The textbooks used are called Hanyu or Zhongwen, kindly donated by Overseas Chinese Affairs Office of the State Council. Teachers are mainly Chinese immigrants. Most of these Chinese schools are non-profit organizations. Therefore, school funds mainly come from Overseas Chinese Affairs Office of the State Council, local overseas Chinese organizations and students' tuition. In recent years, there is an increasing trend in learning Chinese. More and more students from Belgian primary and secondary schools join in to learn Chinese. A growing number of non-Chinese students enroll in Chinese schools. In addition, some schools even open local dialect courses apart from standard mandarin classes to meet children and parents' requests. Such as Ancheng Chinese School have Cantonese courses.

Although there are university students attending the after-hours Chinese schools for adults, the majority of the students are from outside the university such as people whose work requires Chinese. Many students are seniors who are fascinated by Chinese culture or are eager to travel to China. The teaching hours are mainly weekday evenings or weekends. They usually have their set materials for teachings. Some teachers also prepare their own teaching materials. Students' levels range from beginners to advanced.

\section{Conclusion}

Overall, Chinese teaching and learning has been very well promoted in Belgium. There is a coexistence of academic and non-academic education. Local Chinese teachers complement the teachers and volunteers sent by Hanban in China. There are various courses available to Chinese major students, non-Chinese major students, primary and secondary schools students, employees who require Chinese, retirees, as well as oversea Chinese kids. On top of that these courses completely cover from beginners level to advanced studies. It is fair to say that Belgium has made tremendous achievement in terms of Chinese education, management or teachers resources. At the same time, there is room for improvement. 
Firstly, the Sinology deparment in KU Leuven focuses on students' comprehensive skills such as listening, speaking, reading and writing and aims to nurture practical talents. In comparison, University Gent attaches more importance on nurturing students to be academics who have rich Chinese linguistic knowledge and high literature achievement. Therefore, they provide good learning options for potential students. However, both universities fail to demonstrate their focuses from the curriculum's point of view. For instance, there are not enough class hours for modern Chinese in the Sinology department of KU Leuven, and the credits for modern Chinese amount to a small proportion of the total credits too. There are totally 806 class hours for modern Chinese in the three years, accounting for only 50 percent of the total class hours. What's more, as students in senior grades have mastered a certain amount of Chinese vocabularies and the complete grammar system, we should create more opportunities for students to practice their Chinese, in order to further improve their Chinese level. However, there are only 8 class hours of modern Chinese of each week for grade three students, and 5 for grade four students. Which results in most of the students spend more time learning culture or economics, rather than Chinese. Therefore, they can only make a small progress in their Chinese listening, speaking, reading and writing skills for the rest of the two years. From the credits perspective, students in the Sinology department of KU Leuven who intend to get a bachelor's degree should get 138 public credits and 42 optional credits, but there are only 78 credits for modern Chinese courses, accounting for only $43.3 \%$ of total credits. In addition, students should write a book review as their degree thesis for both bachelors' degree and masters' degree. However, the books that they read and the thesis that they write are in English or Dutch, rather than Chinese. The only thing that shows their professional features are that the contents of the books should be relevant to China and the abstract of the thesis should be written in Chinese. Such arrangement will not be conducive to further improve students' Chinese language skills. University Gent set many classes such as Chinese History, Chinese News Reading, Chinese Literature etc apart from their standard language classes. However, there is a large proportion of Asian Culture and History, Buddhism, Oriental Literature, Eastern Asian Linguistics etc. Although these courses broadens students' academic horizon at a certain degree, it results in an awkward situation where students have limited understanding of each field and without any specialties. It deviates from the department's goal to nurture students to be academics who have rich Chinese linguistic knowledge and high literature achievement. In terms of the modern Chinese teaching materials, both universities have textbooks for intensive reading classes. But teachers have to prepare materials by themselves for classes like listening, speaking, writing and translation. In a way, it's beneficial to have vivid language materials for students. The disadvantage would be lacking in grammar knowledge as these materials can be randomly chosen. As teachers for the advanced classes are allocated by Hanban in China, generally, each teacher stays for two years, everyone would be choosing different materials and this way it would be very difficult to achieve certain degree of balance. Consequently, this may affect their teaching qualities. As students lack in systematic Chinese grammar knowledge as their foundation, it would restrict them from improving their Chinese. This is an important issue that both universities should not overlook. Although their Chinese teachers are aware of this issue and are trying to make a more suitable syllabus. Currently, everything is at the elementary stage. They do not have a ready made syllabus with specific teaching guidance.

Secondly, the geographical position of the four Confucius Institutes in Belgium is fairly reasonable, and each has their unique features. They provide excellent services through organizing various activities, such as 'promoting Chinese teaching, training teachers, providing Chinese teaching resources, providing Chinese culture and education information and Chinese - foreign language \& culture exchange etc'(Confucius College Charter). At the moment, although there is nothing about 'Chinese test' and the 'certificate for Chinese teacher's qualification', which is written in Confucius Institutes' Charter. The HSK exam held in University Gent and the special training courses for potential Chinese teachers in Sinology department of KU Leuven (Specifiek Leraren Opleiding, in short SLO) should be able to satisfy all Chinese learners in Belgium. Therefore, it's not necessary for Confucius Institute to 
invest in their time, energy and finances in this area. Chinese language teaching is one important function of Confucius Institutes. Also, we need to consider the practical logistics, for instance, if the Leuven Confucius Institute and the CLT ( Centrum Voor Levende Talen school) are next to each other. They almost share the same curriculum and target students. In addition, there are three weekend Chinese schools and a number of evening schools in Brussels. These schools are most capable of undertaking the children and adult's classes from Brussels Confucius Institutes. Taking everything into consideration, I would recommend these two Confucius Institutes to abandon their current Chinese teaching courses. Instead, they should concentrate on promoting Chinese education and culture a more flexible way. For example, they can invite experts or scholars to train Chinese teachers on a regular basis. This way, they can ensure their Chinese teaching quality. Also, they can set up interesting and relevant courses such as translation, travel, business, finance and Chinese TCM etc. They can also set up optional courses for local university students who are Chinese majors.Develop new teaching methods such as using radio, TV and online etc to meet the needs of more Chinese learners. Develop suitable textbooks for regional students. There is a special need for these materials in the Dutch region where students do not have much Chinese and Dutch materials. The Confucius Institute would be able to complement and cooperate with other Chinese teaching organizations in a harmonious manner and pave the way for their future work.

Last but not the least, most Chinese teachers working at the weekend Chinese school are either local Belgian teachers or Chinese immigrants. They are well familiar with local culture and fully aware of students' learning pattern. They are able to teach in students' mother tongue and Chinese during the class. However, a number of the teachers do have problems such as their mandarin is not good enough for teaching or lacking in basic theoretical knowledge or need to improve their teaching methods. In some worse cases, some of these Chinese teachers have never received proper teaching qualifications. Therefore, this may affect their teaching quality. On the one hand, Confucius Institute would be able to organize professional trainings to these teachers and improve their teaching skills. On the other hand, it's a mutual effort for both China and Belgium to set clear rules for Chinese teachers and guarantee the teaching quality. Just as professor Zhao Jinming said"Training qualified overseas Chinese teachers is the key point for developing Chinese International Education.”(Zhao,2011)[10].

\section{Acknowledgements}

Research Project of Qujing Normal University named "Error analysis of Belgian learners' use of comparative sentences" (No. 2015 QN006).

\section{References}

[1] Chinese Education Sector in Belgium: Information about World Education, (1996) No.6 p.1-4(In Chinese).

[3] Z.Q Yu, J.Yu, Adult Education in China,(1997)No.8, p45-46.(In Chinese).

[4] A Zi, Education in Shanghai,(2008).No.7,p40-41.(In Chinese).

[5] R Ma, Adult Education in China, (1998) No.8, p45-46 (In Chinese).

[6] Y.Y Li, Journal of Shanxi Institute of Education, (2002)No.11,p19-24.(In Chinese).

[7] B.Dessein, Chinese Classics and Culture (1998)No.3, p123-126.(In Chinese).

[8] H.J Liu, H.Y Zhang, Overseas Chinese Education,(2013)No.1,p3-98.(In Chinese).

[9] H.J Liu, Journal of Yunan Normal University (Teaching and Research on Chinese As A Foreign Language Edition),(2012)No.6, p84-89.(In Chinese). 
[10] T Shen, Work and Study Abroad(2011)No. 22,p200.(In Chinese).

[11]J.M Zhao, Language Teaching and Research,(2011).No.4, p87.(In Chinese). 